\title{
A humanização do parto e da equipe multiprofissional como instrumento de
}

\section{rompimento com a violência obstétrica}

The humanization of birth and the multiprofessional team as an instrument for breaching obstetric

\author{
violence
}

\section{La humanización del nacimiento y el equipo multiprofesional como instrumento para abrir la violencia obstétrica}

\section{Resumo}

A parturição sempre foi um momento especial na vida das mulheres, por ser responsável pela transição no papel feminino que passa a ser mãe. O objetivo do estudo é discorrer sobre a violência obstétrica abordando a contribuição da enfermagem na humanização da parturição. Trata-se de uma revisão bibliográfica integrativa com abordagem qualitativa, realizada por meio de pesquisa em revistas eletrônicas, livros e a legislação pertinente a temática. A violência obstétrica viola a dignidade da parturiente e deixa traumas e problemas psicológicos, sendo assim, a humanização do parto e da equipe multiprofissional é um importante instrumento para romper com essa prática. Os dados evidenciaram a necessidade de uma legislação que defina esse tipo de violência bem como criminalize estipulando penas repressivas. Evidenciou-se que a enfermagem possui um papel importantíssimo na assistência à parturiente, pois trata-se do profissional que permanece mais tempo ao lado do paciente em parturição, que houve da mãe seus medos e anseios quanto ao parto. Nesse sentido, ouvir a mãe e lhe transmitir segurança respeitando esse momento é reconhecer a mulher enquanto sujeito central da parturição, esse reconhecimento efetiva o princípio da dignidade humana. No que tange a humanização é imprescindível o envolvimento de todos profissionais que assistem à parturiente em ações de formação continuada e capacitações frequentes.

Palavras-chave: Violência obstétrica; Humanização; Equipe multiprofissional.

\begin{abstract}
Parturition has always been a special moment in women's lives, as it is responsible for the transition from the female role to motherhood. The aim of the study is to discuss obstetric violence addressing the contribution of nursing in the humanization of parturition. This is an integrative literature review with a qualitative approach, carried out through research in electronic journals, books and legislation relevant to the subject. Obstetric violence violates the dignity of the parturient and leaves trauma and psychological problems, so the humanization of childbirth and the multidisciplinary team is an important instrument to break this practice. The data highlighted the need for legislation to define this type of violence as well as criminalize it by stipulating repressive penalties. It was evident that nursing has a very important role in assisting the parturient, as it is the professional who spends more time next to the parturient patient, who had their mother's fears and anxieties about childbirth. In this sense, listening to the mother and transmitting her security, respecting this moment, is recognizing the woman as the central subject of the parturition, this recognition makes the principle of human dignity effective. With regard to humanization, the involvement of all professionals who assist the parturient in continuing education and frequent training actions is essential.
\end{abstract}

Keywords: Obstetric violence; Humanization; Multiprofessional team.

\section{Resumen}

El parto siempre ha sido un momento especial en la vida de las mujeres, ya que es responsable de la transición del rol femenino a la maternidad. El objetivo del estudio es discutir la violencia obstétrica, abordando la contribución de la 
enfermería a la humanización del parto. Se trata de una revisión bibliográfica integradora con enfoque cualitativo, realizada a través de la investigación en revistas electrónicas, libros y legislación relevante en la materia. La violencia obstétrica atenta contra la dignidad de la parturienta y deja traumas y problemas psicológicos, por lo que la humanización del parto y el equipo multidisciplinario es un instrumento importante para romper con esta práctica. Los datos destacaron la necesidad de una legislación que defina este tipo de violencia y la criminalice al estipular penas represivas. Se evidenció que la enfermería tiene un papel muy importante en la asistencia a la parturienta, ya que es la profesional que pasa más tiempo al lado de la parturienta, que tenía los miedos y ansiedades de su madre por el parto. En este sentido, escuchar a la madre y transmitir su seguridad, respetar este momento, es reconocer a la mujer como sujeto central del parto, este reconocimiento hace efectivo el principio de dignidad humana. En lo que respecta a la humanización, es fundamental la implicación de todos los profesionales que asisten a la parturienta en la formación continua y las acciones formativas frecuentes.

Palabras clave: Violencia obstétrica; Humanización; Equipo multiprofesional.

\section{Introdução}

Historicamente até o final do século XVIII o parto era uma prática que envolvia exclusivamente às mulheres, sendo realizados no ambiente doméstico com auxílio de parteiras. A parturição era vista como um ato fisiológico, no entanto, no final do século XIX o parto passou a ser considerado um procedimento médico-hospitalar, rompendo com a exclusividade feminina começando a inserir a figura masculina nesse processo (Zanardo et al., 2017).

No Brasil, o Sistema Único de Saúde registrou em seu departamento de informações - DATASUS o montante de 98,08\% dos partos hospitalares, apresentando um número significativo no crescimento de partos cesárea entre os anos de 2007 a 2015. Nesse aspecto, o crescimento de cirurgias cesariana indicam a necessidade de discussão sobre a temática, isso porque a maioria destas, são consideradas desnecessárias, ou seja, não haviam riscos a saúde da gestante nem do bebê, o que é contra a indicação (Zanardo et al., 2017).

O parto consiste em um momento especial na vida da mulher, além de fazer a transição social de papéis, na qual a mulher passa a exercer o papel de mãe. Entretanto, esse evento perpassa por aspectos psicológicos, emocionais e sociais, sendo vivida de forma individual para cada mulher, onde a cultura tem forte influência (Leal, et. al., 2018).

A partir dos levantamentos históricos descritos na literatura por Queiroz et al. (2017) e considerados neste estudo, pôde-se perceber que a V.O advém de uma violência contra mulher e que se refere a questões de gênero. Isso significa que a construção social e simbólica de uma mulher, está quase sempre associada à uma dominação masculina, pois, as relações de poder que se estabeleceram entre ambos, constituem uma relação desigual e de inferiorização. No contexto médico e obstétrico, essa relação se repete. O seu corpo se torna objeto controlado pela prática médica.

Considerando o crescimento por partos hospitalares e o aumento de cirurgias cesáreas sem indicações clínicas, se evidencia a necessidade de pesquisas e estudos que abordem a assistência ao parto, considerando todas as peculiaridades da gestação desde o pré-natal até o pós-parto, rompendo assim com a cultura de violência. Outrossim, é reafirmar a importância do parto humanizado e do respeito aos direitos da parturiente atendendo ao princípio da dignidade humana que é a base central em um estado democrático (Menezes et al., 2020).

A violência obstétrica-VO é uma prática frequente e considerada normal por muitos profissionais de saúde, a mesma está atrelada a questão de gênero. Consiste em uma violência institucional, exercida por equipe médico-hospitalar e se caracteriza pela negligência ou maus-tratos a gestantes desde a assistência ao pré-natal até o pós-parto. Sendo assim, a VO pode ser definida como maus tratos físicos, verbais e psicológicos, ou até mesmo, práticas e desnecessárias como: tricotomia, ocitocina de rotina, episiotomia, realizar cesariana sem indicação ou até mesmo privar a parturiente de acompanhante (Tesser et al., 2015).

Assim, percebe-se que a violência é a imposição de um grau significativo de dor e sofrimento que se pode evitar e a violência obstétrica é tida como um tipo específico de violência contra a mulher, onde geralmente ocorre a violação dos 
direitos da mulher grávida em processo de parto, incluindo a perda da autonomia e a decisão sobre seu corpo, fatos estes que muitas vezes causam sofrimento psíquico irreversível na mulher (Lange, 2016).

Tais práticas ferem o direito da gestante em receber um atendimento digno e humanizado, sendo um risco a saúde e integridade física, além de ferir a dignidade humana, em suma, é uma violação aos direitos humanos. Segundo Cunha Junior (2019) a dignidade da pessoa humana assume relevo como valor supremo de toda sociedade para o qual se conduzem todos os direitos fundamentais da pessoa. É uma qualidade intrínseca e distintiva de cada ser humano que o faz merecedor do mesmo respeito e consideração por parte do Estado e da comunidade, implicando, neste sentido, um complexo de direitos e deveres fundamentais que assegure a pessoa tanto contra todo e qualquer ato de cunho degradante e desumano.

A VO é caracterizada pela Lei Orgânica sobre os Direitos das mulheres a uma Vida Livre de Violência como uma forma de apropriar-se do corpo e das decisões femininas no processo reprodutivo, praticado por profissionais de saúde que tratam desumanamente, usam medicamentos e intervenções desnecessárias e contraindicadas sobre a parição, contrariando os desejos e a autonomia da gestante. De acordo com estudos realizados pela Fundação Perseu Abramo, em 2010, 25\% das mulheres afirmaram ter sofrido violência obstétrica, o mais terrível é que muitos profissionais consideram essa prática natural durante a parição (Menezes et al., 2020).

Nesse contexto, a formação do profissional obstetra e a política de humanização no parto são imprescindíveis para romper com a cultura da violência, maus tratos e palavras culturalmente reproduzidas como: "para fazer não chorou, agora aguenta", causam traumas na vida de mulheres em um período que seria um sonho para muitas. A VO é uma prática que deve ser repudiada por profissionais de saúde, a assistência no parto não pode ferir a dignidade da pessoa humana e nem violar os direitos da parturiente (Sena; Tesser, 2017).

O estudo é de suma importância para ampliação dos conhecimentos técnicos profissionais, bem como a desmitificação e naturalização da V.O. Estudos mostram que há uma dificuldade por parte dos profissionais em reconhecerem esse tipo de violência, no entanto, mulheres relatam sofrimento nesse momento tão importante de suas vidas. Aprofundar em estudos possibilita um entendimento crítico do que é a V.O. bem como humanizar a assistência rompendo, assim, com essa violência cruel.

A violência obstétrica é uma espécie de violência contra a mulher bem específica, uma vez que ocorre contra o momento reprodutivo da mulher e dentro das unidades de saúde, públicas ou privadas, tendo como principais causadores os profissionais da saúde, em especial, médicos e enfermeiros. Esse tipo de violência pode ocorrer em quatro momentos, quais sejam: durante a gestação; no parto; no pós-parto; e em casos de aborto. Em suma, o estudo partiu da seguinte problematização: Qual a contribuição da política de humanização do parto e da equipe multiprofissional para o rompimento com a violência obstétrica?

Sendo assim, o objetivo do estudo é discorrer sobre a violência obstétrica abordando a contribuição da enfermagem na humanização da parturição. Considera-se que a humanização na assistência é fundamental para o bem-estar das mulheres em período gravídico, portanto, formação continuada contribuem para mudança de comportamento da equipe multiprofissional o que fortalece e resguarda o direito da mulher durante o parto.

\section{Metodologia}

\subsection{Tipo de estudo}

O estudo consiste em uma revisão bibliográfica integrativa com abordagem qualitativa, método que agrupa a produção científica relevante acerca de um tema preestabelecido, ofertando acesso rápido e sintetizado aos resultados científicos de maior acuidade para a área estudada, estabelecida por meio de artigos publicados que se propôs a identificar as consequências físicas e psicológicas que acometem as mulheres vítimas da violência obstétrica. Conforme alude Perovano 
(2016) os desenhos qualitativos visam a obtenção de um panorama amplo, holístico, profundo e intenso do conteúdo e contexto da investigação, sendo assim, é a abordagem utilizada para elucidação da temática proposta no estudo.

\subsection{Coleta de dados}

No estudo foram investigados artigos publicados nas bases de dados Biblioteca Virtual em Saúde (BVS), Literatura Latino-Americana e do Caribe em Ciências da Saúde (LILACS) e Scientific Eletronic Library Online (SciELO). Foi realizado também consulta a sites da Organização Mundial da Saúde (OMS), Portarias e Leis do Ministério da Saúde, livros e revistas especializadas no tema.

Utilizarão como descritores para a consulta às bases de dados: violência obstétrica, consequências físicas e psicológicas. Serão analisados cerca de 22 artigos, 2 Portarias, 1 Lei, 3 publicações da OMS e uma Pesquisa Nacional "Nascer no Brasil" publicada pela FIOCRUZ na língua portuguesa e apresentando um recorte temporal de 2015 a 2021.

\subsection{Critérios de inclusão e exclusão dos artigos}

Os artigos inclusos foram publicados nos últimos 6 anos em português e inglês que abordam a violência obstétrica e suas consequências físicas e psicológicas para a mulher fazendo uma relação com a pratica multiprofissional que atuam na prática da parição, e estão disponibilizados eletronicamente na íntegra e excluídos os artigos que foram publicados fora do limite temporal 2015 a 2021 e que não estejam disponíveis eletronicamente na íntegra.

Tabela 1: Critérios de inclusão e exclusão.

\begin{tabular}{l|l}
\multicolumn{1}{c|}{ INCLUSÃO } & \multicolumn{1}{c}{ EXCLUSÃO } \\
\hline Artigos publicados de 2015 a 2021 & Artigos anteriores a 2000 \\
Estudos em Língua Portuguesa e inglesa & Estudos em Língua espanhol \\
Que abordam sobre mulheres em processo de & $\begin{array}{l}\text { Que abordam outras situações que não seja à } \\
\text { referente ao parto } \\
\text { parturição } \\
\text { Que discorrem sobre a prática de enfermagem e } \\
\text { equipe multiprofissional obstétrica } \\
\text { Textos completos }\end{array}$ \\
obstetrícia/parto \\
Texto incompletos
\end{tabular}

Fonte: Autores (2021).

Após fazer a pré-leitura dos artigos filtrados e selecionados com base nos critérios de inclusão e seleção, restaram 22 (vinte e dois) artigos que subsidiam a presente pesquisa. Os dados coletados foram tratados utilizando a Técnica de Análise de Conteúdo de Bardin (2017) que analisa a temática sob três momentos: a pré-análise, a exploração do material e o tratamento dos resultados que consiste na interpretação dos estudos.

\section{Resultados e Discussão}

\subsection{O princípio da dignidade humana}

Os princípios constituem-se como alicerce e base do ordenamento jurídica, na qual define a lógica e a racionalidade do sistema, traçando rumos a serem seguidos pela sociedade e pelo Estado. Eles consagram ideias fundamentais e informadoras da organização do estado no que diz respeito às leis para que funcionem como linhas mestras para coerência geral em sua aplicabilidade (Messa, 2018).

A dignidade da pessoa humana dentro do ordenamento jurídico brasileiro é o princípio máximo, assegurado pelo artigo $1^{\circ}$, III, CF 88 que afirma que a República Federativa do Brasil é um Estado Democrático de Direito e tem como fundamentos, entre outros, a dignidade da pessoa humana (Brasil, 1988). 
Ao estudar os conceitos que envolvem a palavra Dignidade o estudioso Nunes (2018) ressalta que o conceito de Dignidade não pode ser relativizado, sendo assim, independe do sentido de bem e mal. Diz respeito as condições mínimas existenciais para uma vida saudável, além de propiciar e promover sua participação ativa e co-responsável nos destinos da própria existência e da vida em sociedade.

Em conformidade Silva (2016) afirma que a "[...] a dignidade da pessoa humana constitui um valor que atrai a realização dos direitos fundamentais do homem, em todas as suas dimensões, e, como a democracia é o único regime político capaz de propiciar a efetividade desses direitos, o que significa dignificar o homem, é ela que se revela no valor supremo, o valor que a dimensiona e humaniza (Silva, 2016, p. 28)".

É na dignidade humana que se concretiza toda efetivação do direito constitucional, sendo, portanto, respaldo jurídico de toda efetivação dos direitos fundamentais. De acordo com Fulterleib (2016, p. 80) a "[...] expressão dignidade da pessoa humana dirige-se ao homem concreto e individual, a expressão dignidade humana é entendida como qualidade a todos os seres humanos".

Sendo assim, Fulterleib (2016) diz que a dignidade está relacionada com a idéia de personalidade o que torna evidente que são invioláveis os direitos contra a personalidade. Conceituar e caracterizar a dignidade é algo complexo no campo jurisdicional, Silva (2016) alude que a doutrina afirma que o termo foge as formulações gerais, a dignidade é um corpo semântico pouco preciso.

De acordo com o entendimento do Filósofo Immanuel kant (1724-1804) a dignidade humana está diretamente relacionada com a liberdade, isto significa que o homem é livre, porém sua liberdade tem limites que é até a dignidade do outro. O Brasil tem o princípio da dignidade humana como princípio supremo "[...] a dignidade humana é o conceito central do Estado constitucional democrático (Barzotto, 2015, p. 40)".

Cleber Francisco Alves (2016) enfatiza que somente no século XX com o surgimento dos regimes democráticos que são concebidos direitos e liberdades individuais om o intuito de assegura à Pessoa Humana tratamento igualitário. A Dignidade no Estado Democrático de Direitos faz a distinção da Pessoa Humana dos demais seres reconhecendo-o enquanto sujeito de direitos.

Em análise a história percebe-se que somente eram consideradas pessoas no âmbito jurídico os indivíduos que desempenhavam papéis excepcionais na sociedade. Porém, o princípio da dignidade humana tem respaldado na ideologia de igualdade entre os homens, ou seja, todo indivíduo é um sujeito com os mesmos direitos (Garcia, 2016).

A dignidade humana nasce com a pessoa, ou seja, é inata, inerente à sua essência. O indivíduo ao nascer já traz consigo direitos quanto a sua integridade física e psíquica, portanto, aspectos de sua personalidade têm que ser respeitados, tais como pensamento, ações e comportamento essas características compõem a sua dignidade (Sarlet, 2016).

De acordo com esse pensamento Sarlet (2016) atribui a Dignidade à própria condição humana da pessoa, isto significa que a dignidade do ser humano não pode ser renunciada pelo mesmo em função de sua condição enquanto humano. Sendo assim, a dignidade humana vem assegurar todos os demais direitos sociais, e isso inclui o direito a saúde.

\subsection{Conceituando o fenômeno da violência}

A violência é um fenômeno social que tem crescido significativamente nos últimos anos. Tal fenômeno permeia por todas as classes sociais, sendo assim, é necessário buscar compreensão para enfretamento dessa realidade social contemporânea. Segundo Silva (2016) "a violência possui ligações profundas com a desigualdade entre as classes e a exclusão social, dessa forma seu enfrentamento não pode eximir-se da melhoria do sistema de proteção social, do fortalecimento das políticas sociais e da garantia de direitos (Silva, 2016, p. 20)".

A violência não é um fenômeno local, mas universal, na qual envolve todos os indivíduos que convivem em uma 
sociedade, sejam no papel de vítimas ou provocadores da violência.

O conceito de violência é abordado de diferentes maneiras de acordo com cada estudioso, segundo Chauí (1999) o conceito de violência pode ser definido como:

- Desnaturar: tudo o que age usando a força para ir contra a natureza de algum ser;

- coagir, constranger, torturar, brutalizar: todo ato de força contra a espontaneidade, a vontade e a liberdade de alguém;

- $\quad$ violar: todo ato de violação da natureza de alguém ou de alguma coisa valorizada positivamente por uma sociedade;

- todo ato de transgressão contra aquelas coisas e ações que alguém ou uma sociedade define como justas e como um direito;

- é um ato de brutalidade, sevícia e abuso físico e/ou psíquico contra alguém e caracteriza relações intersubjetivas e sociais definidas pela opressão, intimidação, pelo medo e pelo terror.

A violência é expressão da questão social, que vem tomando proporções maiores principalmente pelas mudanças na qual a sociedade vem passando na área de produção e reprodução das relações sociais. Nesse aspecto, a violência sofrida deve ser entendida analisando todo contexto social que sofre diferentes tipos de violência (Dias, 2019).

A violência é um fenômeno que cresce diariamente de forma assustadora. Entende-se que são vários os fatores que contribuem para esse crescimento. O estresse social é considerado um desses fatores, as pessoas estão mais impacientes e agressivas em decorrência do estresse vivido pela pressão social (Dias, 2019).

Nesse aspecto, conceituar a violência não é algo fácil, visto que esse fenômeno envolve fatores histórico, a cultura, a relação e o contexto na qual comportamento se deu. É um grande equívoco definir a violência sem contextualizá-la com a realidade na qual ela está inserida, não há definição sem associar o fenômeno à realidade social (Motta; Lovato, 2020).

Segundo Motta e Lovato (2020) outro fator essencial para definir um comportamento violento é a questão cultural, pois os comportamentos são determinados pela cultura de um povo. Para exemplificarmos, podemos citar a questão da autoridade de que o esposo tem sobre a esposa na índia, onde é permitida a agressão à mulher por parte do esposo, diferentemente no Brasil essa prática é tida como crime não sendo aceitável na nossa cultura, embora exista.

A Organização Mundial de Saúde (OMS) define a violência como o uso de força física ou poder, em ameaça ou na prática, contra si próprio, outra pessoa ou contra um grupo ou comunidade que resulte ou possa resultar em sofrimento, morte, dano psicológico, desenvolvimento prejudicado ou privação (OMS, 2016)).

O conceito dado pela OMS envolve os aspectos desde a intencionalidade com a realização do ato, isso independente da ação produzida. Nesse conceito ficam excluídos os acidentes não intencionais. A violência é tida como uma questão de saúde pública, isso porque afeta a saúde individual e coletiva, portanto é necessário tratamento e prevenção contra esse fenômeno.

A violência, pelo número de vítimas e pela magnitude de sequelas orgânicas e emocionais que produz, adquiriu um caráter endêmico e se converteu num problema de saúde pública em muitos países (...). O setor Saúde constitui a encruzilhada para onde convergem todos os corolários da violência, pela pressão que exercem suas vítimas sobre os serviços de urgência, atenção especializada, reabilitação física, psicológica e assistência social (Organização Panamericana da Saúde, 2016, p. 5).

A violência é um fenômeno que meche com toda estrutura social, percebe-se que cresce o número de estudos e discussão sobre a temática, no entanto, pouco se enfatiza sobre a prevenção e políticas públicas voltadas para diminuir a 
violência, as chamadas políticas de inclusão social.

Sendo assim, a violência pode ser definida como um ato de constrangimento físico ou moral pelo uso de força ou coação contra alguém; um exercício desproporcional de poder que ameaça a integridade física, emocional, religiosa, familiar ou profissional de alguém. Atualmente, a violência é uma ameaça à saúde pública no mundo, pois afeta a integridade física e mental dos indivíduos, das famílias e da sociedade (Teles; Melo, 2018).

Dentre os tipos de violência, a obstétrica constitui-se como um desrespeito à mulher no que diz respeito ao processo reprodutivo, negando à mulher sobre seu direito de decidir sobre seu corpo, ressaltando que o uso indevido e abusivo da medicalização também está inserido na violência obstétrica (Menezes et al., 2019).

\subsection{A Violência obstétrica e suas implicações sociais e psicológicas}

Até o século XIX as questões pertinentes ao parto era exclusivamente a mulher, sendo uma experiência privada da parturiente e suas parteiras, tratava-se de uma solidariedade feminina, na qual as mulheres se apoiavam no processo do parto que muitas vezes ocorria no próprio lar (Menezes et al., 2019).

No entanto, a ruptura com a cultura do parto doméstico sendo o mesmo transferido ao ambiente hospitalar trouxe a necessidade de profissionais qualificados para realizarem tal procedimento o que ocasionou o processo de despersonalização da mulher parturiente. Sendo assim, a parturição hospitalar transformou-se em um evento médico, solitário e medicalizado (Leal et al., 2017).

Destaca-se a mitificação de que o local mais seguro, nos dias atuais, para parturição é no ambiente hospitalar. O acompanhamento por profissionais da saúde é inquestionável, no entanto, a mulher não pode ser privada de seus direitos quanto as especificidades do parto. O parto hospitalar não pode ser uma ferramenta de violência nem de opressão ao desejo da parturiente quanto ao seu corpo, daí a necessidade de uma assistência humanizada (Pereira et al., 2016).

No estudo de Menezes et al., (2020) destaca a prática de maus-tratos físicos tanto físicos quanto psicológicos, toques sem consentimento ou conhecimento da necessidade pela parturiente, negligência as alegações de dores e frases irônicas e desrespeitosas, tais frases causam danos psicológicos e emocionais. Destaca-se ainda a falta de preparo profissional e a ausência de estrutura para se ter um parto humanizado.

Nesse aspecto, a VO é considerada uma violação aos direitos da mulher em estado gravídico em parição, trata-se de uma apropriação do processo reprodutivo das mulheres por profissionais de saúde, por meio de práticas e técnicas desumanas, dolorosas e muitas vezes contraindicadas. Importante salientar que essa violência atinge número maior de mulheres negras, usuárias de drogas, presas ou portadoras do vírus HIV (Sena; Tesser,2017).

Segundo Sena e Tesser (2017) a violência obstétrica está tipificada nas seguintes práticas:

- Proibição de acompanhante seja parceiro ou outra pessoa de confiança da parturiente;

- Realização de procedimentos sem a ciência da gestante;

- Realizar procedimentos sem a autorização prévia da gestante;

- Submeter a parturiente à procedimentos sem necessidades que tragam a mesma dor e constrangimento como: tricotomia, enema, toques, limitação de movimentos, entre outros;

- Tratar a parturiente com falta de empatia, palavras irônicas, ser rude, ríspido, piadas;

- Distanciar o bebê da presença da mãe sem justificativa clínica;

A V.O. está relacionada com a violência de gênero perpetuada no seio da sociedade em detrimento da cultura patriarcal que se tem sobre a figura feminina de incapacidade e limitações. A mulher desde os tempos primórdios que é considerada como o sexo mais frágil, sendo, portanto, submissa nas relações familiares e sociais. Portela e Silva (2017) relata a história da sociedade brasileira que ainda traz marcas de relações baseadas no modelo patriarcal - mesmo que com o passar dos 
anos isso tenha diminuído - o que significa uma visão de homem provedor, que detém a força, o controle, a inteligência e considera a mulher como um ser frágil, com o dever de obedecer, procriar e ser um exemplo de moral e bons costumes.

Assim, a relação de poder do homem sobre a mulher, pode-se comparar com a posição que esta ocupa no momento do seu parto, e o papel que o médico exerce sobre a mesma, já que, nesse contexto, a autonomia da mulher também não é respeitada e suas vontades não são consideradas. São ideias que partem das construções sociais e históricas do lugar e papel da mulher perante a sociedade, principalmente em relação à submissão ao sexo masculino e pela forma que essa posição é assumida por ela (Portela; Silva, 2017).

Nessas relações de poder, no processo de parturição se evidencia que a figura médica se enquadra no topo dessa hierarquia social na área da saúde, não apenas por deter uma autoridade pelo o seu conhecimento científico, "mas também em relação à cultura e à moral, dominando muitas vezes a conduta, os valores e as crenças de cada pessoa" (Queiroz et al., 2017). Essa relação - profissional e parturiente - de interação e de possíveis violências, inicia no momento que as opiniões dos profissionais podem influenciar em todo processo de trabalho de parto da mulher ignorando seus direitos sobre seu corpo.

A V.O. é uma prática frequente nas unidades de saúde, no entanto, ainda se percebe uma invisibilidade dessa questão social, isso porque muitos profissionais cometem essa violência por ser uma prática costumeira e segundo esses profissionais sem intenção de trazer sofrimento a vítima o que torna difícil a identificação dessa violência. Lange (2016) em suas pesquisas levantou o questionamento: "a reflexão que se pode fazer se dá no sentido de imaginar que se a própria V.O é considerada invisível, como reconhecer as marcas psicológicas decorrentes desta violência?". Pois, se há dificuldades em identificar as violências físicas desse fenômeno, imagina-se como ainda é desafiante encontrar os efeitos emocionais dele.

Importante salientar que mesmo havendo vários estudos que discorrem sobre a V.O. e suas consequências danosas a saúde da mulher, no Brasil não possui legislação específica para caracterizar e punir esse tipo de violência. Caso a mulher sinta-se ferida os seus direitos a mesma pode recorrer a via jurisdicional e peticionar apenas danos morais, visto que esse tipo de violência não está tipificado em leis. A inexistência de leis que coíbam essa prática contribui para perpetuação da V.O. e fere o direito de milhares de mulheres em um momento muito especial de suas vidas (Pedroso; Lopez, 2017).

O Ministério da Saúde-MS publicou uma nova orientação relacionada ao termo "V.O". No dia 3 de maio de 2019 o MS orientou que o termo deveria ser evitado e até retirado dos documentos de políticas públicas, pois, para o governo, o uso se refere a um significado intencional da força violenta contra a mulher na assistência ao parto, o que generaliza a prática médica nesse momento, já que não são em todas as situações que a expressão é aplicada (Brasil, 2019).

Para o Ministério da Saúde-MS, "tanto o profissional de saúde quanto os de outras áreas, não têm a intencionalidade de prejudicar ou causar dano". Esta foi uma medida motivada pelas entidades médicas que acompanham o parecer publicado pelo Conselho Regional de Medicina (CFM) em 2018, que afirmou que o termo V. O. são uma agressão contra a ciência médica e suas especialidades (Brasil, 2019).

De acordo com Diniz et al., (2016) as orientações publicadas pelo MS podem ser uma reafirmação para prática da violência obstétrica, daí a necessidade de legislação que caracterize e defina esse tipo de violência. Não se pode negar o sofrimento vivido por milhares de mulheres que alegam ter sofrido maus-tratos ou ouviram piadas no momento do parto, visto que esse tipo de violência traz sérios problemas a saúde psíquica da mulher, além de que fere o princípio da dignidade humana que é o princípio basilar do nosso ordenamento jurídico.

\subsubsection{Tipificação de violências}

Os estudos de Sena (2016) reconhecem o caráter multifatorial e multidimensional da violência obstétrica, podendo a mesma se apresentar das seguintes formas: violência institucional do tipo psicológica, estrutural, física, verbal, moral, discriminatória e sexual. 
De acordo com Marrero e Bruggemann (2018) a violência institucional inicia-se antes da hospitalização com a peregrinação da parturiente em busca de atendimento, caracterizando uma violência estrutural e prolonga-se até o parto com a ocorrência das outras variações de violência contra a mulher em trabalho de parto e parto, sendo que, na maioria dos casos, há ocorrências concomitantes de mais de um tipo de violência. Nesse aspecto, é importante frisar que a ausência de assistência à mulher em situação gravídica é uma violência, isso porque o direito a saúde está resguardado na Carta Magna.

A violência estrutural foi descrita como falta de acesso das mulheres a serviços substanciais e a peregrinação das mesmas em diferentes maternidades para receber atendimentos. Quando se consegue o suporte as gestantes podem se deparar com a inadequação da estrutura física das instituições para o atendimento, a imposição de rotinas institucionais que não levam em consideração as necessidades e direitos das parturientes e déficit de pessoal para prestar o atendimento digno e de qualidade no parto. A baixa qualificação da equipe assistencial, o conflito entre classes profissionais e a deficiência de recursos materiais para o auxílio ao parto também foram apontados como esse tipo de violência (Martins; Barros, 2016).

Em detrimento do sucateamento do Sistema Único de Saúde-SUS há muitos relatos de mulheres que sofreram a peregrinação por falta de leitos em unidades hospitalares no momento da parturição. Sendo assim, a ampliação de leitos e a melhoria da estrutura das maternidades é imprescindível para redução desse tipo de violência (Zasciurinski, 2016).

As violências psicológica e verbal se caracterizam pelo uso de comentários com a intenção de denegrir a mulher e negar sua autonomia durante o período do parto. São identificados julgamento e culpabilização da mulher, xingamentos, hostilidades e gritos, abuso verbal, humilhação das mulheres grávidas, palavras, expressões de ironia, comentários desrespeitosos, reprimendas e ameaças de abandono. Estudos demonstraram que é comum o uso de piadas sobre a dor na qual a mulher esteja sentindo com o intuito de justificar sua intensidade, outra ação bem recorrente, alegada por vítimas, são o uso de intervenções, como o toque, sem justificativas (Martins; Barros, 2016).

A violência física se caracteriza como prática obstétrica não recomendada pelas evidências científicas, nesse aspecto, as intervenções cirúrgicas sem indicação configuram V.O. isso porque, cabe a mulher decidir sobre sua parição em detrimento do seu direito sobre seu corpo. O uso de manobras como manobras de expulsão no parto, também é considerado violência. Marreno; Bruggemann, 2018).

Em conformidade Souza, Silva e Alves (2016) complementam como formas de manifestações desse tipo de abuso o recebimento de autorização para intervenções com base em informações limitadas ou distorcidas, como mentir para a paciente quanto à sua dilatação ou vitalidade fetal, forjando indicações que não são verdadeiras tais como macrossomia fetal, mecônio, circulares cervicais, desproporção cefalopélvica, para indicar cesariana devido a interesses pessoais, a negação de informações à mulher sobre sua condição e sobre a evolução do parto e a manipulação da mulher sem orientação prévia dos cuidados realizados ou mesmo a realização de procedimentos sem o consentimento da mulher.

Por violência moral identifica-se a violência mais associada às condutas profissionais. São exemplos dessa forma de violência: o não reconhecimento da mulher como elemento principal do parto e a colocação do médico nesse lugar, cabendo a ele a autoridade, responsabilidade e a condução ativa desse processo, controlando e se apropriando desse evento, reforçando o nascimento não como uma experiência fisiológica, mas como um evento de riscos potenciais (Barbosa; Machado, 2017).

A violência discriminatória está relacionada com a classe social da mulher, sendo mais frequente em mulheres negras, presas ou pobres, na qual devido sua condição sócio financeira é ignorada em suas peculiaridades no processo de parição. Independente de classe social, raça ou situação financeira a mulher é um sujeito de direitos e a discriminação fere todos os princípios constitucionais pertinentes a pessoa humana (Marreno; Bruggemann, 2018). 


\subsection{Humanização do parto e da equipe multiprofissional}

A humanização do parto abrange um conjunto de condutas e conhecimentos que objetivam o bem-estar da parturiente, sendo de suma importância para redução da mortalidade materna e perinatal. Portanto, trata-se de uma política que para sua efetivação é fundamental o envolvimento de todos os profissionais bem como uma estrutura física apta a execução de um parto humanizado (Silva et al., 2019).

Os usos de práticas humanizadas no parto são recomendadas pela OMS desde 1996, destacando a atenção no acolhimento, orientações sobre seus direitos enquanto parturiente, aceitação por parte da equipe multiprofissional quanto a posição e movimentos de desejo da mulher no processo de parturição. Sendo assim, o saber médico e a assistência da enfermagem devem colocar como foco central a mulher, utilizando-se de manobras e técnicas de forma humanizada (Silva et al., 2019).

Segundo Nascimento et. al. (2020) humanizar o parto não se limita à realização do parto normal, utilizar ou não técnicas e procedimentos, mas sim promover a mulher a protagonista e não mera expectadora, propiciando a ela toda tomada de decisão. Humanização consiste no respeito ao processo fisiológico do nascimento, e em caso de intervenções proceder com informações claras e precisas dando segurança a parturiente sobre suas decisões.

O Ministério da Saúde institui o Programa de Humanização no Pré-natal e Nascimento-PHPN através da portaria 569 publicada no ano de 2000, com o intuito de reduzir as altas taxas de morbi-mortalidade materna e perinatal, garantindo a parturiente o seu direito de decisão no processo de pré-natal e parturição. O programa possui dois eixos fundamentais que se refere a postura ética e solidária por parte da equipe multiprofissional e o outro o atendimento com dignidade da mulher gestante (Brasil, 2018).

O parto humanizado pode ser definido como aquele pautado no respeito à mulher que lhe proporciona autonomia $\mathrm{e}$ protagonismo feminino. Deve ocorrer sem intervenções, sem cesárea eletiva, sem ocitocina, sem manobras de expulsão, sem fórceps, sem episiotomia, e as intervenções que se seguem no recém-nascido como nitrato de prata, aspiração nasal e gástrica etc., ou seja, é imprescindível que ocorra de forma mais natural possível (Zasciurinksi, 2016).

O modelo humanizado surge no próprio Ocidente como um movimento de reação aos excessos da tecnocracia, apresentando uma concepção holística do corpo e da gravidez, novas formas de vivenciar o parto, e que, consequentemente, passa a disputar o seu lugar de legitimidade no campo biomédico. Traz a ideia de conexão da gestante com múltiplos aspectos pessoais, do seu corpo, família, sociedade, saúde e com os profissionais de saúde, e reconstrói uma noção fisiológica do parto (Pedroso; Lopez, 2017).

Nesse aspecto, a enfermagem tem um papel importante no acompanhamento das gestantes, isso porque são eles que mais estão próximos desde o pré-natal. Sendo assim, é imprescindível que os enfermeiros (as) estejam em educação permanente e engajados em prestar atendimento solidários à necessidade da parturiente, fornecendo-lhes todas informações necessários para o bom andamento do processo de parturição (Nascimento et al., 2020).

Em conformidade Souza et al. (2019) diz que profissionais atenciosos e cuidadosos contribuem significativamente na qualidade da assistência médico-hospitalar prestada no parto. Destacando que o parto humanizado é aquele que repeita a dignidade e os direitos da parturiente. Portanto, em um parto humanizado quanto menor a intervenção de técnicas desnecessárias melhor para sua concretização, isso porque respeita a fisiologia humana do nascimento.

A enfermagem obstétrica tem respaldo legal no Decreto $n^{\circ}$ 94.406/87 na qual incumbe esse profissional na assistência a parturiente e o parto normal. Sendo assim, o estudo de Vargens, Silva e Progianti (2017) afirma que a enfermagem obstétrica possui conhecimentos e técnicas humanizadas para o parto humanizado, respeitando a autonomia da mulher, o que é imprescindível para garantir qualidade no processo de parturição. 
O enfermeiro obstetra no momento do parto é o profissional que dialoga com a mulher, buscando uma relação de parceria e companheirismo, instrumentalizando-a na dor do parto. Essa relação é fundamental para dar segurança à mulher, pois a reconhece enquanto sujeito principal na parturição, destacando-se que esse momento de dor a mesma irá apresentar vários comportamentos, que em outra situação não teria, daí a necessidade de compreendê-la e de orientá-la com respeito e ética (Vargens; Silva; Progianti, 2017).

Atualmente tem crescido significativamente as discussões sobre a assistência humanizada no parto, isso devido ao crescimento do número de cesáreas e do uso excessivo de medicamentos. Estudos revelam que o parto é algo fisiológico e o corpo da mulher está preparado para esse momento, no entanto, percebe-se que esse evento é mais demorado e requer atenção meticulosa por parte dos profissionais. Sendo assim, opta-se sem nenhuma indicação clínica pela cesariana por entender ser mais rápido a sua execução, no entanto, uma cirurgia é um trauma e deve ser realizado somente quando houver necessidade (Silva et al., 2019).

Este modelo de cuidados permite às mulheres familiaridade e tranquilidade com o processo de nascimento e tem como meta a redução das taxas de cesáreas e morbimortalidade materna e perinatal, consideradas problema de saúde pública, uma vez que o uso excessivo de tecnologias vem causando mais danos do que benefícios à mulher e ao bebê (Russo et al., 2017).

A formação dos profissionais de saúde, em especial dos médicos, tem papel determinante no desenho atual da assistência e na resistência à mudança. $\mathrm{O}$ conjunto da educação dos profissionais tem sido alvo de críticas pela dificuldade de prepará-los com formação humanista. Com isso, a relação deixa de ser entre humanos e passa a ser uma relação sujeito-objeto, do médico com a doença (Diniz et al., 2016).

Segundo Souza et al. (2016), humanizar a relação profissional de saúde-usuário e os serviços de saúde exige profundas transformações da formação e da valorização de novos saberes; aquisição de uma postura mais próxima da equipe com os usuários; rediscussão do modelo excessivamente biológico da medicina; e adoção de maior responsabilidade política e ideológica dos gestores. Além da teoria, a humanização deve ser praticada na relação entre professores e alunos e alunos e instituição de ensino, assim, é possível não só garantir a humanização na prática, mas também no decorrer do ensino. A prática da humanização na formação de profissionais de saúde é importante para a prevenção e diminuição no índice de ocorrências de violência obstétrica, pois possibilita o acolhimento, a escuta da gestante e o protagonismo da mulher no parto.

As implicações decorrentes da violência obstétrica configuram grandes impactos negativos e individuais na vida de cada mulher, de modo que alcançam dimensões psicossociais e físicas. Propostas de humanização da prática médica devem ser abordadas desde o início acadêmico objetivando a sua aplicação futura que, por conseguinte, contribuirá para uma melhor relação médico-paciente. Visto isto, o modelo de humanização da assistência a parturientes se torna alternativa imprescindível para que se consiga minimizar e/ou abolir abusos banalizados e imperceptíveis pela má formação médica.

\section{Conclusão}

O estudo realizado evidenciou que a violência obstétrica é uma realidade em muitas unidades de saúde, e que devido à falta de estudos e discussão dessa temática muitas mulheres sofrem essa violência sem saberem que estão sendo vítima de uma agressão em um momento tão especial de suas vidas. Ressaltando que a V.O. traz consequências psicológicas e físicas para mulher na qual muitas vezes ela carregará pelo resto de sua vida.

Sendo assim, a violência obstétrica ocasiona nas mulheres traumas tanto físicos quanto psicológicos, evidencia-se que a utilização de procedimentos invasivos tem crescido no campo da obstetrícia, mesmo havendo controvérsias em relação as suas aplicações. E que de fato ocasiona inúmeras consequências as mulheres, para tal afirmação, podemos citar como exemplo as complicações e riscos da cesárea, que possui alto índice de mortalidade e morbidade para a mãe e para o bebê. 
Destaca-se que os danos físicos são inúmeros, no entanto, a V.O. não se limita somente a isso, vai além, e pode ocasionar também danos psicológicos, que precisam ser abordados cada vez mais, principalmente em estudos e pesquisas para obtermos uma transformação de paradigma, porém, compreendemos que este processo pode ser demorado e gradual, todavia, é totalmente necessário.

O PHPN norteia a prática de enfermagem obstétrica para o atendimento humanizado durante o processo de parturição, na qual devem ser respeitados os direitos da mulher. Entende-se que o papel da enfermagem é imprescindível para concretização desse programa, isso porque é o profissional que fica mais tempo assistindo a parturiente, portanto, a relação de respeito e compreensão é fundamental para o êxito da humanização do parto.

Evidencia-se que a humanização no parto é uma ferramenta importantíssima para romper com a cultura de V.O., nesse aspecto, a formação continuada da equipe multiprofissional para práticas humanizadas na assistência ao parto é uma necessidade de muitas unidades de saúde. Portanto, capacitar os profissionais de forma contínua se faz necessário para o atendimento humanizado em todas suas especificidades.

Para instituir uma assistência humanizada visando reduzir ou até mesmo eliminar as complicações que as intervenções podem ocasionar nas mulheres, é necessário um trabalho em conjunto dos gestores e profissionais de saúde para oferecer um atendimento digno as gestantes, e proporcionar informações sobre o referido tema para que as pessoas saibam diferenciar o que é um procedimento necessário de um ato violento, podendo assim intervir e não deixar os seus direitos ofuscados e mascarados pela relevância em um achismo de que é normal. Salientando ainda a importância de uma educação continuada desses profissionais de saúde, proporcionado debates e inovações das técnicas utilizadas na medicina obstétrica, bem como suas consequências na vida da mulher.

Entende-se que a temática possui poucos estudos, sendo assim, faz-se necessário primeiramente o aprimoramento de estudos sobre a VO bem como o despertar do poder público para regulamentar em lei a definição desse problema social. O aprofundamentos de estudo é fundamental para romper com essa violência desumana é um momento tão especial na vida da mulher.

Em suma, pode-se afirmar que os objetivos propostos inicialmente no estudo foram alcançados, mesmo havendo escassez de estudos publicados e legislação especifica sobre a temática, foi possível discorrer sobre as consequências da V.O. bem como sobre a humanização do parto enquanto ferramenta para romper com esse ciclo.

\section{Referências}

Alves, C. F. (2016). Justiça Processo e Direitos Humanos. Lumen Juris.

Barbosa, L. C., Fabbro, M. R. C. \& Machado, G. P. R. (2017). Violência obstétrica: pesquisas qualitativas. Revista Enfermagem. $35(2)$ ), $190-207$.

Bardin, L. (2017). Análise de Conteúdo. Martins Fontes.

Barzotto, L. F. (2015). A Democracia na Constituição. Unisinos.

Brasil. (1988). Constituição Federal do Brasil. http://www.planalto.gov.br/ccivil_03/constituicao/constituicao.htm.

Brasil. (2019). Ministério da Saúde reconhece legitimidade do uso do termo 'violência obstétrica'. Globo. https://g1.globo.com/ciencia-esaude/noticia/2019/06/10/ministerio-da-saude-reconhece-legitimidade-do-uso-do-termo-violencia-obstetrica.ghtml.

Chauí, M. (1999). Uma Ideologia Perversa. Folha de São Paulo, Caderno Mais.

Cunha Júnior, D. (2019). Curso de Direito Constitucional. JusPodivm.

Dias, M. B. (2019). A Lei Maria da Penha na Justiça. Editora Juspodiuvm.

Diniz, S. G., Salgado, H. D. O., Andrezzo, H. F. D. A., Carvalho, P. G. C. D., Carvalho, P. C. A., Aguiar, C. D. A., NIY, D. Y. (2016). Violência obstétrica como questão para a saúde pública no Brasil: origens, definições, tipologia, impactos sobre a saúde materna, e propostas para sua prevenção. Revista Brasileira de crescimento e desenvolvimento humano. Journal of Human Growth and Development, 2015, $25(3)$ : $377-376$. 
Garcia, E. (2016). Dignidade da pessoa humana: referenciais metodológicos e regime jurídico. Fórum.

Lange, M. (2016). Outras dores além do parto: um estudo de caso com mulheres vítima da violência obstétrica. Santa Catarina. https://riuni.unisul.br/handle/12345/3077.

Leal, S. Y., Lima, V. L. A., Silva, A. F. da, Soares, P. D. F. L., Santana, L. R., Pereira, A. (2018). Percepção de enfermeiras obstétricas acerca da violência obstétrica. Cogitare Enfermagem. http://dx.doi.org/10.5380/ce.v23i1.52473.

Lovato, C. dos S., Motta, V. S. (2020). Descrição dos perfis socioeconômico e sociocultural de vítimas e de agressores envolvidos em casos de violência contra a mulher: um estudo de caso. Revista de ciências Humanas e Sociais. V. 6, n. 3.

Marrero, L., \& Bruggmann, O. M. (2018) Violência institucional durante o processo de parturição no Brasil. Revista Brasileira Enfermagem, 71(3), 11521161 .

Martins, A. C., \& Barros, G. M. (2016). Você vai dar à luz na dor? Revisão integrativa da violência obstétrica em unidades públicas brasileiras. Revista Dor, $17(3), 215-218$

Menezes, F. R. de., Reis, G. M., Sales, A. A., Jardim, D. M. B., \& Lopes, T. C. (2020). O olhar de residentes em Enfermagem Obstétrica para o contexto da violência obstétrica nas instituições. Interface, 1807-5762.

Messa, A. F. (2018). Direito constitucional. Rideel.

Nascimento, E. R. do, Santos, E. C. da S., Sousa, D. S. de., \& Gallotti, F. C. M. (2020). Desafios da assistência de enfermagem ao parto humanizado. Ciências Biológicas e de Saúde Unit. Aracaju. 6(1).

Nunes, A. R. (2018). O princípio da dignidade da pessoa humana. Editora Saraiva Jur.

Organização Mundial de Saúde (2016). Declaração da OMS sobre Taxas de Cesáreas. OMS. http://apps.who.int/iris/bitstream/10665/16 1442/3/WHO_RHR_15.02_por.pdf?ua=1.

Pedroso, C. N. L. S., Lopez, L. C. (2017) À margem da humanização? Experiências de parto de usuárias de uma maternidade pública de Porto Alegre-RS. Physis, Rio de Janeiro, v. 27, n. 4, p. 1163-1184.

Pereira, J. S., Silva, J. C. O., Borges, N. A., Ribeiro, M. G., Aurek, L. J., \& Souza, J. H. (2016). Violência obstétrica: ofensa à dignidade humana. Brazilian Journal of Surgery and Clinical Research - BJSCR, 15(1), 103-108.

Perovano, D. G. (2016). Manual de metodologia da pesquisa científica. Intersaberes,

Portela, A., \& Silva, E. (2017). A psicologia dialogando com a violência obstétrica e o direito da mulher: uma revisão bibliográfica. In: V Seminário internacional enlaçando sexualidades, 10, 2017, Recife, Anais... Faculdade Franssinetti do Recife.

Queiroz, T. C., Fófano, G. A., \& Andrade, M. F. (2017). Violência obstétrica e suas perspectivas na relação de gênero. Revista Científica Fagoc Saúde, v. 2.

Russo, J., N. M., Silva, F. L., \& Chazan, L. K. (2019). Escalando vulcões: a releitura da dor no parto humanizado. Mana 25 (2).

Sarlet, I. W. (2016). Dignidade da pessoa humana e Direitos Fundamentais CF 1988. Livraria do Advogado.

Silva. J. A. da. (2016) Curso de direito constitucional. Malheiros.

Silva, T. M. A., Góis, G. A. S. de., Filgueiras, T. F., \& Candeia, R. M. S. (2019). Significados e práticas da equipe de enfermagem acerca do parto humanizado: uma revisão da literatura. Brazilian Journal of Surgery and Clinical Research-BJSCR. Vol.26, n.1.

Sena, L. M. (2016). Ameaçada e sem voz, como num campo de concentração: a medicalização do parto como porta e palco para a violência obstétrica. Tese, Florianópolis: Universidade Federal de Santa Catarina.

Sena, L. M., \& Tesser, C. D. (2017). Violência obstétrica no Brasil e ociberativismo de mulheres mães: relato de duas experiências. Interface 21 (60) • JanMar.

Souza, A. B., Silva, A. C., \& Alves, R. N. (2016). Fatores associados à ocorrência de violência obstétrica institucional. Revista Ciência Médica, 25(3), 115128.

Souza, F. M. de L. C.., Santos, W. N. dos., Santos, R. S. da C., Rodrigues, O. B., Santiago, J. da C. D., \& Silva, R. A. R. (2019). Tecnologias apropriadas ao processo do trabalho de parto humanizado. Enferm Foco, 10(2): 118-1124.

Teles, M. A. de A., Melo, M. de. O que é violência contra a mulher. Brasiliense.

Tesser, C. D., Knobel, R., Andrezzo, H. F. de A., \& Diniz, S. G. (2015). Violência obstétrica e prevenção quaternária: o que é e o que fazer. Rev Bras Med Fam Comunidade, Rio de Janeiro 1-12.

Vargens, O. M. da C., Silva, A. C. V. da., \& Progiant, J. M. (2017). Contribuição de enfermeiras obstétricas para consolidação do parto humanizado em maternidades do Rio de Janeiro-Brasil. Escola Anna Nery 21(1).

Zanardo G. L.P., Uribe, M. C., \& Nadal, A. (2017). Violência obstétrica no Brasil: uma revisão narrativa. Psicologia e Sociedade, 9.

Zasciurinski, J. M. (2016). Violência obstétrica: uma contribuição para o debate acerca do empoderamento feminino. ttps://www.marilia.unesp.br/Home/Eventos/2015/xiisemanadamulher11189/violencia-obstetrica_juliana-miranda.pdf. 